\title{
Article
}

\section{Amaranth Seed Polyphenol, Fatty Acid and Amino Acid Profile}

\author{
Ovidiu Procopet (1) and Mircea Oroian*
}

Faculty of Food Engineering, Stefan cel Mare University of Suceava, 720229 Suceava, Romania; ovidiu.procopet@fia.usv.ro

* Correspondence: m.oroian@fia.usv.ro

check for

updates

Citation: Procopet, O.; Oroian, M. Amaranth Seed Polyphenol, Fatty Acid and Amino Acid Profile. Appl. Sci. 2022, 12, 2181. https://doi.org/ 10.3390/app12042181

Academic Editor: Massimo Lucarini

Received: 24 January 2022

Accepted: 17 February 2022

Published: 19 February 2022

Publisher's Note: MDPI stays neutral with regard to jurisdictional claims in published maps and institutional affiliations.

Copyright: (c) 2022 by the authors. Licensee MDPI, Basel, Switzerland. This article is an open access article distributed under the terms and conditions of the Creative Commons Attribution (CC BY) license (https:/ / creativecommons.org/licenses/by/ $4.0 /)$.

\begin{abstract}
In this paper, the extraction of polyphenols from amaranth seed using a Box-Benhken design using four factors-ultra-turrax speed, solid-to-liquid ratio (RSL), methanol concentration and extraction time-were studied. There were two responses studied for the model: total phenolic content (TPC) and total flavonoid content (TFC). The factors which influenced the most the extraction of the TPC and TFC were the RSL, methanol concentration and ultra-turrax speed. Twelve phenolic acids (rosmarinic acid, $p$-coumaric acid, chlorogenic acid, vanillic acid, caffeic acid, $p$-hydroxybenzoic acid, protocatechuic acid and gallic acid) and flavonoids (kaempferol, quercetin, luteolin and myricetin) were studied, and the most abundant one was kaempferol followed by myricetin. The amaranth seed is a valuable source of fatty acids, and $16.54 \%$ of the total fatty acids determined were saturated fatty acids, while $83.45 \%$ of the fatty acids were unsaturated ones. Amaranth seed is a valuable source of amino acids, with 9 essential amino acids being reported: histidine, isoleucine, leucine, lysine, methionine, phenylalanine, threonine, tryptophan and valine.
\end{abstract}

Keywords: amaranth seed; extraction; polyphenols; fatty acids; amino acids

\section{Introduction}

Amaranth is a pseudo-cereal which is known to have a high nutritional value thanks to its amino acids, fiber, trace elements, vitamins, flavonoids, phenolic compounds and polyunsaturated fatty acids [1,2]. Amaranth seed is rich in different bioactive and nutritional compounds such as tocopherols, sterols, squalene, fatty acids, phenolic acids, flavonoids (as free molecules of conjugated molecules with sugars or linked to proteins in a complex matrix through covalent or non-covalent links), dietary fibers and peptides [3-6].

The use of amaranth seeds has increased over the last 10 years both in the ordinary diet as well as in the diets of people suffering from certain diseases and in the diets of the people allergic to several types of cereals [7]. Thus, amaranth seeds, considered to be pseudo-cereals, are characterized by high nutritional and functional values, associated with the antioxidant quality and quantity of proteins and lipids $[2,8,9]$. The amaranth seed flour is a well-known source of polyphenols, and it is recommended by doctors to be used in balanced diets [8]. The polyphenols are easily degraded in the intestine of humans and animals because of the abundance of beta-glucosidase enzyme, which liberates the aglyconic moiety of the molecules [10]. Amaranth seed production has become more and more popular among the people interested in their own health and especially among high performance athletes as a consequence of a change in their eating habits [2].

Antioxidants have triggered considerable interest in food technology research. Their availability in various diets and their high potential role in the fight against different diseases such as cancer and neurodegenerative or cardiovascular diseases has been outlined in a variety of studies [11,12].

Some research has shown that amaranth seeds and leaves have antioxidant capabilities when tested in vitro [13]. Thus, the presence of polyphenols in the amaranth seeds has been reported [14], and so has the presence of flavonoids and betalaines [15]. In other research, Amaranthus hypochondriacus seeds have been analyzed, and phenolic compounds 
with antioxidant properties were discovered [10]. The amaranth can be considered a source for the development of new edible products, as it has a high nutritional value, and there is a trend in recent years regarding vegan diets. It is well known that vegetable proteins present functional properties with high potential for human health [16,17].

Extraction of compounds from the matrices is an important process for achieving the structural composition or a fundamental step for obtaining natural medicines. This process is influenced by many factors, such as the particle size of the matrices, solvents, time, technique and temperature [18]. There are various compound extraction methods for vegetable products. One extraction method uses solvents like ethanol, methanol, ethyl acetate or hexane among other solvents. Conventional solvents like methanol and hexane are recognized for their high extraction yield, but for environmental safety, ethanol is a safer alternative. Various extraction techniques can be used, such as mechanical agitation, ultrasounds, homogenization, Soxhlet-type extraction, maceration and supercritical fluid extraction $[8,10,13,15]$. The particle size of the matrix is important because the smaller the particle is, the better the extraction process is. The ultra-turrax was used for its high versatility in the homogenization process in the case of two immiscible systems (solvent and plant material) [19]. Extraction assisted by an ultra-turrax can be used for bioactive compound extraction from plant matrices.

The extraction of compounds from plant matrices using an ultra-turrax has many advantages, such as narrow and uniform particle size distribution, being a fast and low-cost extraction method and being able to generate high extraction rates at a normal temperature through crushing the matrices into smaller particles $[18,20]$. Moreover, under partial negative pressure permeation, high solubility of the compounds from the matrix into the solvent can be obtained. The extraction rate is increased because of the particle reduction, and drastic stirring adds dynamic molecular permeation [20]. The ultra-turrax was used for the extraction of triterpenoid saponins from Pulsatilla herbs [20], organic acids from honeysuckle [18], lignans from Schisandra chinensis fruit [21] and flavonoids from the seeds of Oroxylum indicum [22].

The aim of this study was to evaluate the influence of the ultra-turrax speed, solid-toliquid ratio, methanol concentration and extraction time on the total phenolic content and total flavonoid content from amaranth seed. In addition, the most concentrated solution was used for the identification and quantification of 12 phenolics. The amino acids and fatty acids from the amaranth seed were determined using a GC-MS method.

\section{Materials and Methods}

\subsection{Materials}

Ecological amaranth seed (Amaranthus cruentus) was procured from Driedfruits supplies (Timisoara, Romania). The seeds were authenticated based on their botanical features, and the seeds were kept in paper bags until extraction.

Methanol, Folin Ciocalteu reagent, sodium carbonate, gallic acid, rosmarinic acid, $p$-coumaric acid, chlorogenic acid, vanillic acid, caffeic acid, $p$-hydroxybenzoic acid, protocatechiuc acid, kaempferol, quercetin, luteolin, myricetin, n-hexane, $\mathrm{BF}_{3}$ and $\mathrm{NaCl}$ were purchased from Sigma Aldrich (Steinheim am Albuch, Germany). Fatty acid methyl esters (FAMEs) were purchased from Restek (Bellefonte, PA, USA, 35077).

\subsection{Methods}

\subsubsection{Extraction of Bioactive Compounds}

The extraction of bioactive compounds was carried out according to the Box-Behnken design presented in Table 1. The amount mentioned for each experiment was transferred into a flask, filled to $30 \mathrm{~mL}$ with the corresponding solvent and submitted to ultraturrax. After extraction, the solution was passed to a centrifuge tube and centrifugated for $10 \mathrm{~min}$ at $5000 \mathrm{rpm}$. The supernatant was collected in a 50-mL flask, filled up with the solvent and kept at $-20{ }^{\circ} \mathrm{C}$ prior analysis. 
Table 1. Box-Behnken design of the TPC and TFC from amaranth seed.

\begin{tabular}{ccccc}
\hline No. & Ultra-Turrax Speed (rpm) & RSL & Methanol (\%) & Time (s) \\
\hline 1 & 10,000 & 0.02 & 40 & 60 \\
2 & 10,000 & 0.02 & 60 & 30 \\
3 & 10,000 & 0.01 & 60 & 60 \\
4 & 10,000 & 0.03 & 60 & 60 \\
5 & 10,000 & 0.02 & 60 & 90 \\
6 & 10,000 & 0.02 & 80 & 60 \\
7 & 20,000 & 0.02 & 40 & 30 \\
8 & 20,000 & 0.01 & 40 & 60 \\
9 & 20,000 & 0.03 & 40 & 60 \\
10 & 20,000 & 0.02 & 40 & 90 \\
11 & 20,000 & 0.01 & 60 & 30 \\
12 & 20,000 & 0.03 & 60 & 30 \\
13 & 20,000 & 0.02 & 60 & 60 \\
14 & 20,000 & 0.01 & 60 & 90 \\
15 & 20,000 & 0.03 & 80 & 90 \\
16 & 20,000 & 0.02 & 80 & 30 \\
17 & 20,000 & 0.01 & 80 & 60 \\
18 & 20,000 & 0.03 & 80 & 60 \\
19 & 20,000 & 0.02 & 40 & 90 \\
20 & 30,000 & 0.02 & 60 & 60 \\
21 & 30,000 & 0.02 & 60 & 30 \\
22 & 30,000 & 0.01 & 60 & 60 \\
23 & 30,000 & 0.03 & 80 & 60 \\
24 & 30,000 & 0.02 & & 90 \\
25 & 30,000 & 0.02 & & 60 \\
\hline
\end{tabular}

\subsubsection{Total Phenolic Content Determination}

A total of $0.1 \mathrm{~mL}$ of extract, according to the design presented in Table 1, was mixed in $1.9 \mathrm{~mL}$ water and $0.1 \mathrm{~mL}$ of Folin Ciocalteu reagent. The mixture was then homogenized for $2 \mathrm{~min}$, and after that, $0.8 \mathrm{~mL}$ of $5 \%$ sodium carbonate was added. The mixture was kept at $40{ }^{\circ} \mathrm{C}$ for $20 \mathrm{~min}$ and cooled down in an ice bath to stop the reaction. The total phenolic content was determined at $750 \mathrm{~nm}$, based on a gallic acid calibration curve expressing the results as a gallic acid equivalent (mg GAE/g) [23].

\subsubsection{Total Flavonoid Content Determination}

A total of $0.2 \mathrm{~mL}$ of extract, according to the design presented in Table 1, was mixed with $2 \mathrm{~mL}$ of methanol and $0.1 \mathrm{~mL}$ of $5 \% \mathrm{AlCl} 3$ (prepared in methanol). The solution was left for $30 \mathrm{~min}$ at room temperature, and its absorbance was measured at $425 \mathrm{~nm}$. The concentration was determined based on a quercetin calibration curve expressing the results as $\mathrm{mg}$ quercetin equivalent/L (mg QE/L) [23].

\subsubsection{Individual Phenolic Determination}

The phenolic acids (rosmarinic acid, $p$-coumaric acid, chlorogenic acid, vanillic acid, caffeic acid, $p$-hydroxybenzoic acid, protocatechuic acid and gallic acid) and flavonoids (kaempferol, quercetin, luteolin and myricetin) were determined from the methanolic extract using a Shimadzu high-performance liquid chromatograph (Kyoto, Japan) with a diode array detector. The separation was carried out on a Zorbax SP-C18 column $150 \mathrm{~mm}$ in length, and a 4.6-mm i.d. $5 \mu \mathrm{m}$-diameter particle was used for the separation. Elution was carried out with a solvent system consisting of $0.1 \%$ acetic acid in water (solvent $\mathrm{A}$ ) and acetonitrile (solvent $\mathrm{B}$ ) at a flow rate of $1 \mathrm{~mL} \cdot \mathrm{min}^{-1}$. The determined phenolic compounds of gallic acid, vanillic acid, protocatechuic acid and $p$-hydroxibenzoic acid were determined at $280 \mathrm{~nm}$, and chlorogenic acid, $p$-coumaric acid, caffeic acid, rosmarinic acid, myricetin, quercetin, luteolin and kaempherol were determined at $320 \mathrm{~nm}$ [24]. Figure 1 presents an HPLC-DAD chromatogram at $280 \mathrm{~nm}$ and $320 \mathrm{~nm}$ for the standards $(100 \mathrm{mg} / \mathrm{L})$. 

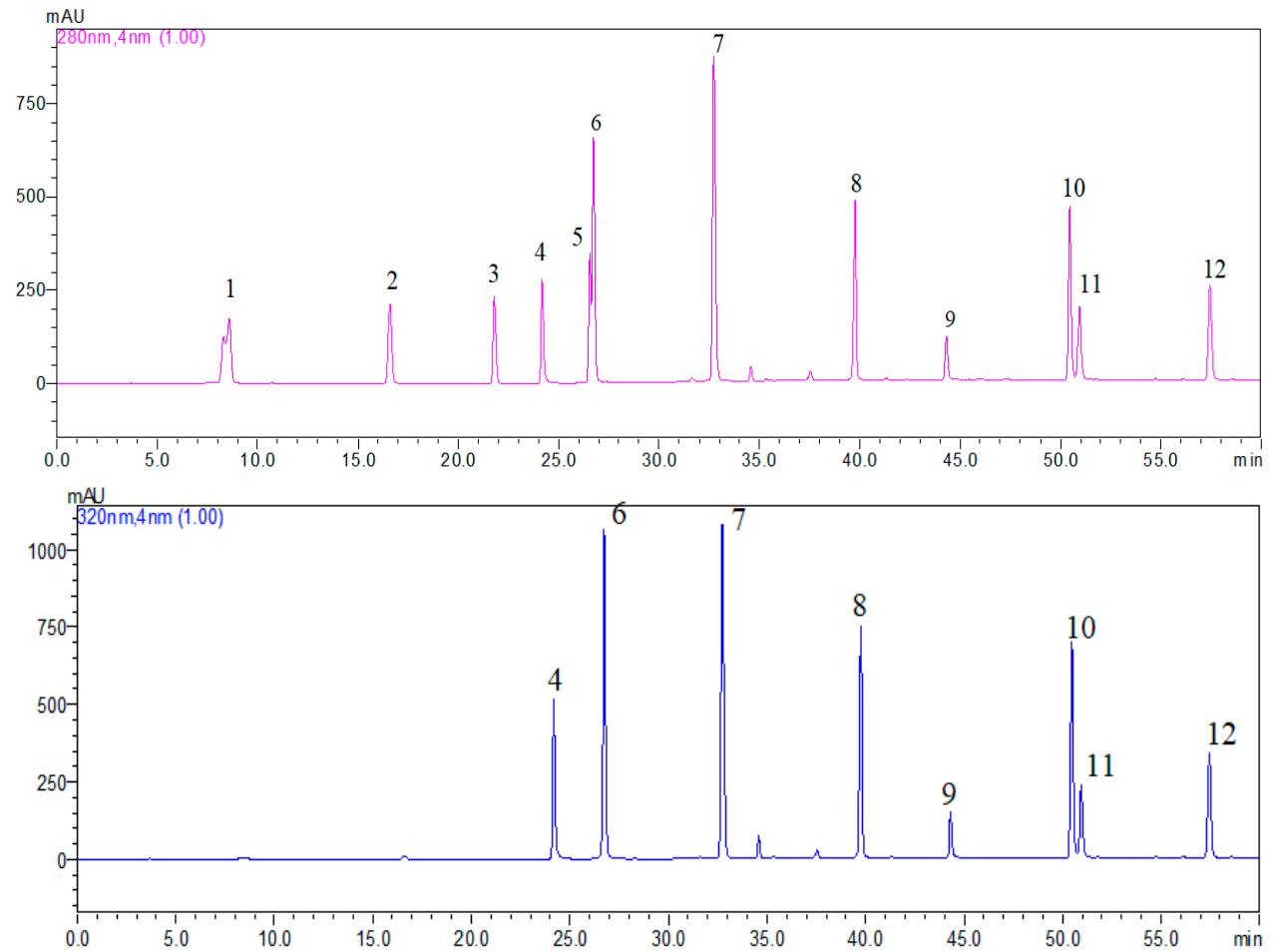

Figure 1. HPLC-DAD chromatogram at $280 \mathrm{~nm}$ and $320 \mathrm{~nm}$ for the standard $(100 \mathrm{mg} / \mathrm{L})$ for gallic acid (peak 1 (8.578 $\mathrm{min})$ ), protocatechuic acid (peak 2 (16.6 min)), p-hydroxybenzoic acid (peak 3 (21.8 $\mathrm{min})$ ), caffeic acid (peak 4 (24.2 min)), vanillic acid (peak 5 (26.6 min)), chlorogenic acid (peak 6 (26.7 min)), p-coumaric acid (peak 7 (32.7 min)), rosmarinic acid (peak 8 (39.8 min)), myricetin (peak 9 (44.3 $\mathrm{min})$ ), luteolin (peak 10 (50.5 min)), quercetin (peak 11 (50.9 min)) and kaempferol (peak 12 (57.4 min)).

\subsubsection{Fatty Acid Profile}

Prior to analysis, the amaranth seed flour was extracted for $48 \mathrm{~h}$ with n-hexane at room temperature. The oil $(0.1 \mathrm{~g})$ was mixed with $1 \mathrm{~mL}$ of $\mathrm{n}$-hexane and $1 \mathrm{~mL}$ of $15 \%$ $\mathrm{BF}_{3}$ in methanol. The mixture was kept for $15 \mathrm{~min}$ at $60^{\circ} \mathrm{C}$ in a water bath. The mixture was cooled to $20^{\circ} \mathrm{C}$ and mixed with $5 \mathrm{~mL}$ of an $\mathrm{NaCl}$-saturated solution, and the solution was centrifuged for $5 \mathrm{~min}$ at $3000 \mathrm{rpm}$ afterward. The supernatant was filtered with a $0.45-\mu \mathrm{m}$ nylon filter and kept at $-20^{\circ} \mathrm{C}$ prior to analysis. The separation of the fatty acid methyl esters (FAMEs) was carried out on a SUPELCOWAX 10 column $(60 \mathrm{~m} \times 0.25 \mathrm{~mm}$ i.d., 0.25- $\mu \mathrm{m}$ film thickness; Supelco Inc., Bellefonte, PA, USA) using a Shimadzu GC-MS instrument (GC MS-QP 2010 Plus, Shimadzu, Kyoto, Japan) equipped with an AOC-01 autoinjector that was used to perform the gas chromatographic-mass spectrometric analyses. Identification of FAMEs was performed by comparing their retention times to those of the known standards (37 component FAME Mix, Restek, Bellefonte, PA, USA, 35077) and the resulting mass spectra to the ones from our database (NIST MS Search 2.0) [24]. The FAMEs were quantified by comparison with the standard curves of the FAME 37 mixture, which was made with different concentrations from 0.1 to $1 \mathrm{mg} \cdot \mathrm{mL}^{-1}$. The results were expressed as $\mathrm{mg}$ of fatty acid per $100 \mathrm{~g}$ of amaranth seed.

\subsubsection{Determination of Free Amino Acids}

For the extraction and identification of free amino acids, $1.75 \pm 0.1 \mathrm{~g}$ of amaranth flour was mixed with $15 \mathrm{~mL}$ of $15 \%$ trichloroacetic acid (TCA). The $\mathrm{pH}$ of the mixture was adjusted to 2.2 with $15 \%$ trichloroacetic acid (TCA) (isoelectric precipitation point of the proteins), and the extract was further diluted to $25 \mathrm{~mL}$ with $15 \%$ TCA [25]. Then, the supernatant was collected and filtered using $0.45-\mu \mathrm{m}$ microfilters, and $100 \mu \mathrm{L}$ of the filtered supernatant was subjected to the determination of organic components using the EZfaast GC-MS kit, following the protocol given by the manufacturer. 


\subsubsection{Statistical Analysis}

Experimental Design and Statistical Analysis

The three-level Box-Behnken design was adapted in this study to investigate and optimize the effect of the independent variables of the ultra-turrax speed $\left(X_{1}\right)$, solid/liquid ratio $\left(\mathrm{X}_{2}\right)$, methanol concentration $\left(\mathrm{X}_{3}\right)$ and extraction time $\left(\mathrm{X}_{4}\right)$ on the TPC and TFC. The coded levels of the variables are shown in Table 1. All calculations and graphics were carried out using the statistical software Design Expert 11 (trial version, Minneapolis, MN, USA). Triplicate experiments were conducted in order to validate the optimal extraction conditions.

The Box-Behnken design was based on a second-order (quadratic) polynomial response surface model using the following equation:

$$
\mathbf{y}=\mathbf{b}_{0}+\sum_{\mathbf{i}=1}^{\mathbf{n}}\left(\mathbf{b}_{\mathbf{i}} \mathbf{x}_{\mathbf{i}}\right)+\sum_{\mathbf{i}=1}^{\mathbf{n}}\left(\mathbf{b}_{\mathrm{ii}} \mathbf{x}_{\mathbf{i i}}^{2}\right)+\sum_{\mathrm{ij}=1}^{\mathbf{n}}\left(\mathbf{b}_{\mathbf{i j}} \mathbf{x}_{\mathbf{i}} \mathbf{x}_{\mathbf{j}}\right)
$$

where $y$ is the predicted response (TPC or TFC), $x_{i}$ stands for the coded levels of the design variable (solvent concentration, time, temperature and ultrasonic frequency (Table 1$)$ ), $b_{0}$ is a constant, $b_{i}$ is the linear effects, $b_{i i}$ is the quadratic effects and $b_{i j}$ is the interaction effects.

\section{Results and Discussion}

\subsection{Box-Behnken Design and Model Fitting}

The Box-Behnken design was applied to study the combined effects of the four parameters (ultra-turrax speed, solid liquid ratio, methanol concentration and time) on the total phenolic content (TPC) and total flavonoid content (TFC) from amaranth seed flour. The regression coefficients of the two proposed models are presented in Table 2. The two models were significant ones $(p<0.05)$, and the F-value was 10.31 for the TPC and 10.29 for the TFC. As can be seen, the two models were significant in terms of variance analysis, and the regression coefficients were higher than 0.90 . For the two parameters studied (TPC and TFC), three parameters (ultra-turrax speed, solid-to-liquid ratio (RSL) and methanol concentration) presented significant linear effects $(p<0.05)$, and the linear effects were higher in the case of the TPC than the TFC. The interaction effects between the parameters studied were not significant ones, while one quadratic effect (methanol concentration) was a significant one. 
Table 2. Analysis of variance of the total phenolic content (TPC) and total flavonoid content (TFC) modeling using the Box-Benhken design.

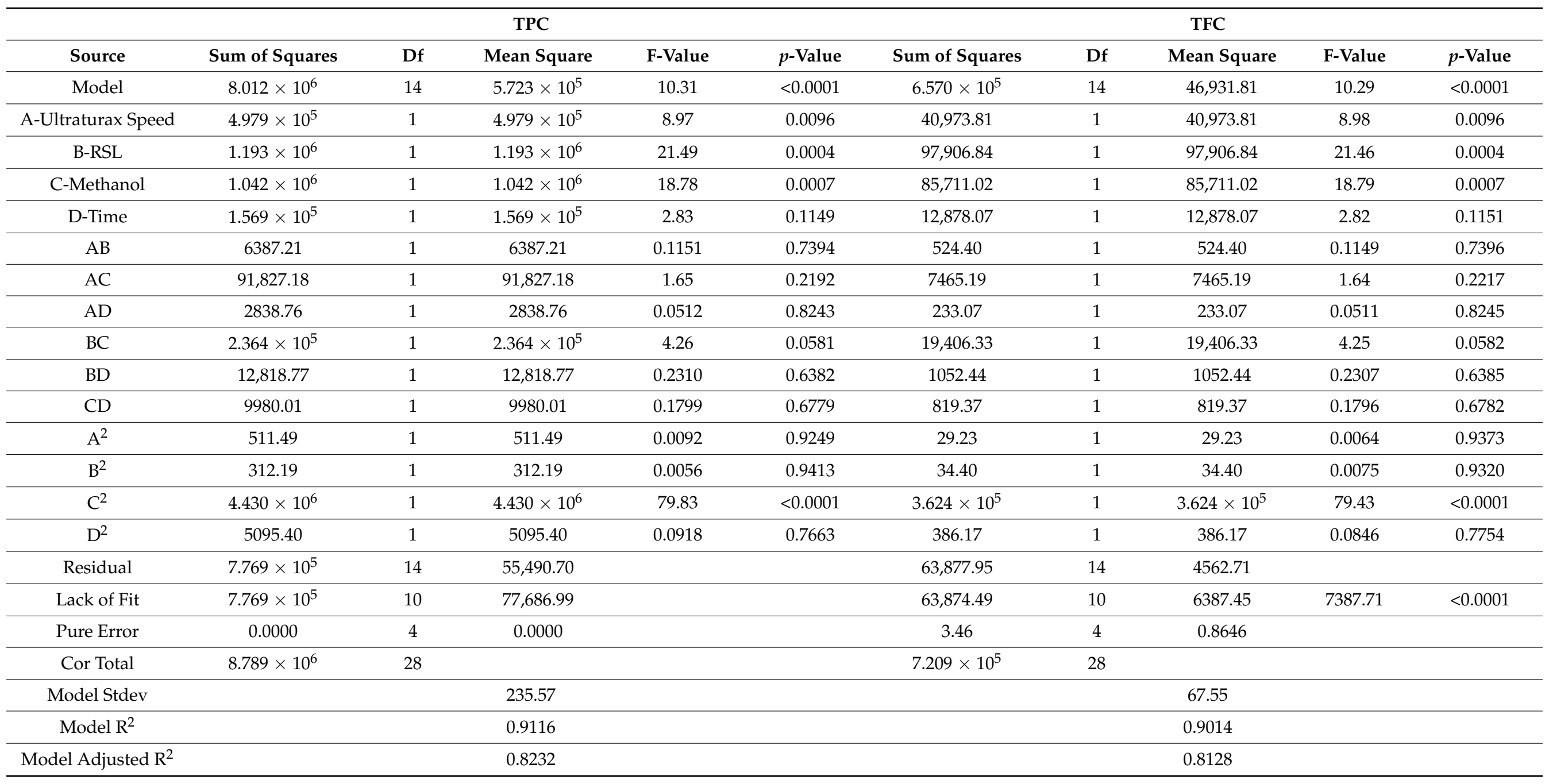




\subsection{Fitting of Second-Order Polynomial Equations}

The relationship between the extraction parameters and experimental data (TPC and TFC) was described using the Box-Behnken design using second-order polynomial equations. The effects which were not significant were eliminated from the equations, and the final equations are presented below:

$$
\begin{gathered}
\text { TPC }=506.2+203.7 \cdot \mathbf{X}_{1}+315.2 \cdot \mathbf{X}_{2}+294.7 \cdot \mathbf{X}_{3}+826.4 \cdot \mathbf{X}_{3}^{2} \\
\text { TFC }=145.7+58.4 \cdot \mathbf{X}_{1}+90.3 \cdot \mathbf{X}_{2}+84.5 \cdot \mathbf{X}_{3}+236.4 \cdot \mathbf{X}_{3}^{2}
\end{gathered}
$$

\subsection{Surface Response 3D Plots}

The surface response methodology is a statistical method used to depict the relationship between two parameters and the experimental data [26]. In our study, the BoxBenhken design was used for the optimization of the TPC and TFC extraction from amaranth seed flour using four parameters (ultra-turrax speed, solid-to-liquid ratio, methanol concentration and time). In Figures 2 and 3, the evolution of the TPC and TFC as a function of the parameters studied are presented.

In the case of the TPC, a positive combined effect of a high RSL and high ultraturrax speed was observed, and a high speed corelated with a high amount of matrices influenced the extraction of phenolic compounds positively. Regarding the combined effect of the methanol concentration and ultra-turrax speed, it can be observed that a high ultra-turrax speed and a high methanol concentration generated a high TPC concentration. Furthermore, at a low methanol concentration, there was a maximum TPC, and one possible explanation for this may be the complex chemical composition of amaranth that includes other polyphenols more soluble in high water solvent concentrations. The combined effect of methanol and RSP showed a maximum point at a high methanol concentration and high RSL, respectively. In the case of time combined with the ultra-turrax speed and RSL, a direct correlation between the TPC concentration and time/RSL can be observed. The combination of the methanol concentration and time shows that the time did not influence the evolution significantly. In the case of the TFC, a positive combined effect of a high RSL and high ultra-turrax speed was observed, and a high speed corelated with high amount of matrices influenced the extraction of phenolic compounds positively. Regarding the combined effect of the methanol concentration and ultra-turrax speed, it can be observed that a high TFC concentration was achieved at the maximum speed and concentration, and at a low methanol concentration, there was a maximum. One possible explanation may be that because of the complex chemical composition of the amaranth, there can be other flavones more soluble in high water solvent concentrations. The combination of the methanol concentration and time shows that the time did not influence the evolution significantly. The combined effect of methanol and RSP showed a maximum point at a high methanol concentration and high RSL, respectively. In the case of time, it can be observed that its combination with the ultra-turrax speed and RSL had a direct correlation between the TPC concentration and time/RSL. 

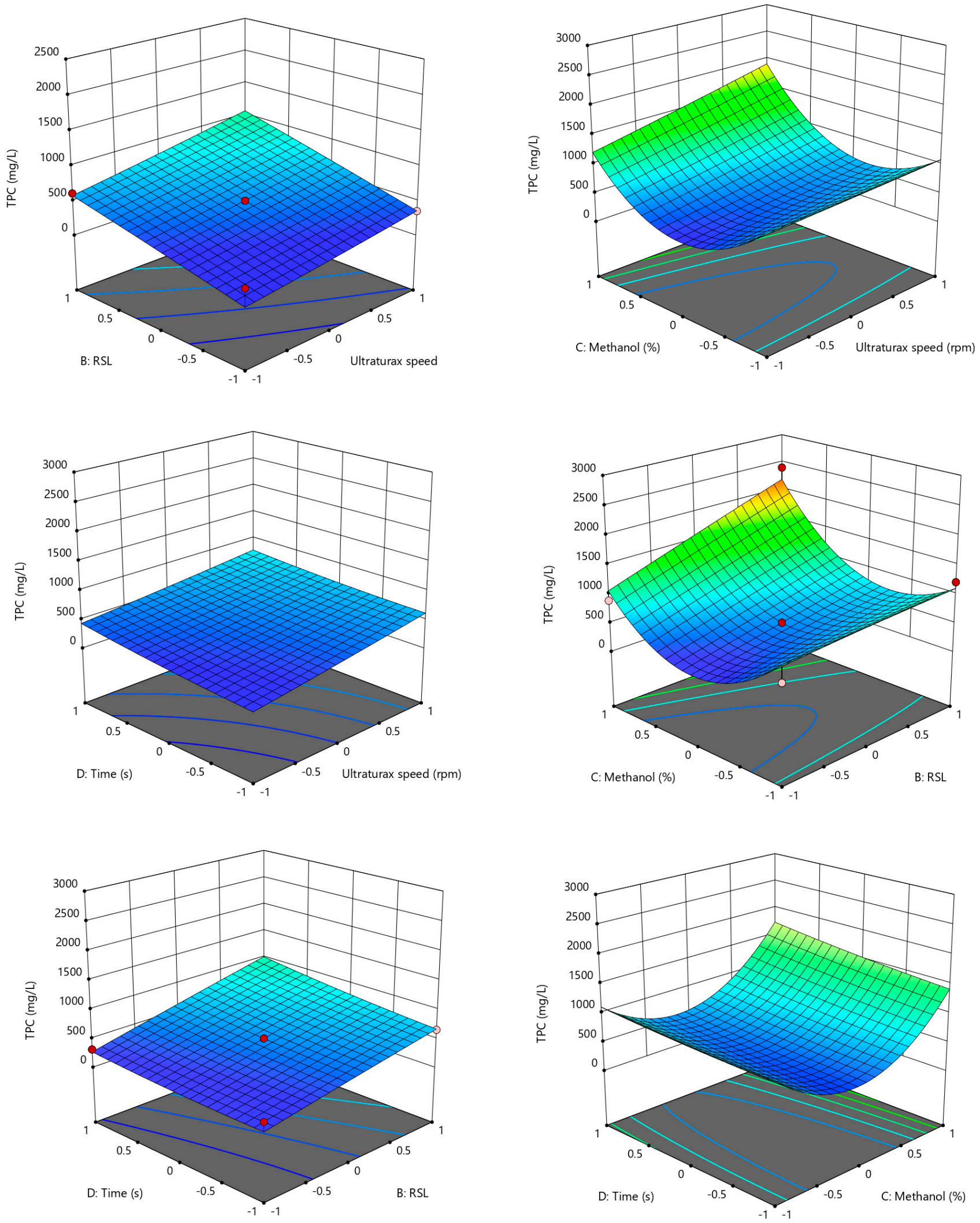

Figure 2. 3D evolution of TPC according to the Box-Benhken design. -1 the low value of the parameter, +1 the highest value of the parameter according to data from Table 1. 

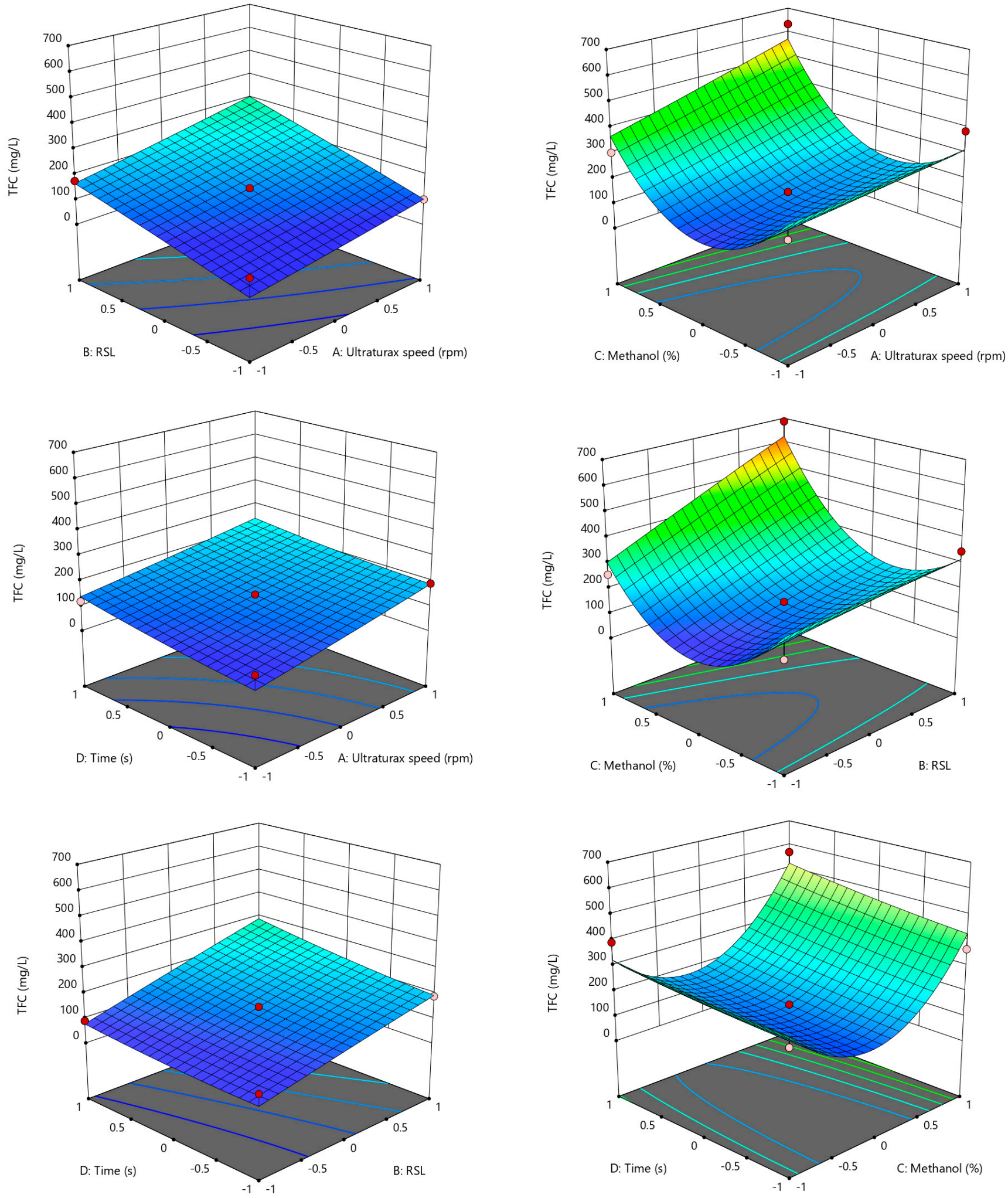

Figure 3. 3D evolution of TFC according to the Box-Benhken design. -1 the low value of the parameter, +1 the highest value of the parameter according to data from Table 1.

\subsection{Individual Phenolic Profile}

Table 3 presents the concentrations of individual phenolics (expressed as $\mathrm{mg} / \mathrm{kg}$ amaranth seed) determined using the chromatographic method. From the 12 compounds considered, 8 were determined (vanillic acids, caffeic acid, chlorogenic acid, $p$-coumaric 
acid, rosmarinic acid, myricetin, luteolin and kaempferol), while 4 were under the limit of detection (gallic acid, protocatechuic acid, 4-hydroxybenzoic acid and quercetin). From the phenolic acids determined, vanillic acid was the most abundant, followed by rosmarinic acid, chlorogenic acid, $p$-coumaric acid and caffeic acid. The most abundant flavonoid was kaempferol, followed by myricetin and luteolin. Barba de la Rosa et al. determined three polyphenols in amaranth seed-rutin $(10.1 \mathrm{mg} / \mathrm{g})$, nicotiflorin $(7.2 \mathrm{mg} / \mathrm{g})$ and isoquercetin $(0.5 \mathrm{mg} / \mathrm{g}$ ) - and regarding phenolic acids, they quantified 4-hydroxybenzoic acid $(2.2 \mathrm{mg} / \mathrm{g})$, syringic acid $(0.8 \mathrm{mg} / \mathrm{g})$ and vanillic acid $(1.8 \mathrm{mg} / \mathrm{g})$ [10]. The polyphenols in amaranth seed present high antioxidative activity and anti-inflammatory capacity as well as miscellaneous effects like anti-fibrotic, anti-bacterial, anti-hypertensive, anti-atherogenic and anti-proliferative effects [27]. Kaempferol, the major phenolic observed in our study, was reported to have a nephroprotective effect, preventing DOX-induced cardiac damage, hippocampal damage and neural and lung ischemia injury as well as an antioxidative effect $[28,29]$. Myricetin, the second-largest phenolic observed, possesses antimicrobial activity and has a positive effect on microbiota [30]. The myricetin supplementation decreases hepatic lipid synthesis and inflammation by modulating the gut microbiota [31].

Table 3. Phenolic profile of amaranth seed.

\begin{tabular}{lc}
\hline Phenolic & mg/kg Amaranth Seed \\
\hline Gallic acid & ND \\
Protocatechuic acid & ND \\
4-hydroxybenzoic acid & ND \\
Vanillic acid & 10.33 \\
Caffeic acid & 3.37 \\
Chlorogenic acid & 4.00 \\
p-coumaric acid & 3.63 \\
Rosmarinic acid & 7.68 \\
Myricetin & 105.05 \\
Luteolin & 39.15 \\
Quercitin & $\mathrm{ND}$ \\
Kaempferol & 1041.50 \\
Total & 1214.71 \\
\hline
\end{tabular}

$\mathrm{ND}=$ not detected.

\subsection{Fatty Acid Composition}

The fatty acid composition of the amaranth seed was found based on the oil extracted from the seeds (7.01\% oil content in amaranth seed). In Table 4 , the fatty acid composition of the amaranth seed is presented. As can be observed, the fatty acid in the highest amount was reported to be oleic acid ( $23.78 \mathrm{mg} / 100 \mathrm{~g}$ amaranth), representing $42.68 \%$ of the total fatty acids, followed by cis,cis-9,12-linoleic acid (C18:2), palmitic acid C16:0 and trans,trans9,12-linoleic acid (C18:2). The saturated fatty acids represented $16.54 \%$, while unsaturated fatty acids represented $83.45 \%$ (poly-unsaturated fatty acids represented $37.56 \%$ ). In a previous study, a higher concertation of saturated fatty acids (26.72-27.28\%) and lower concentration of unsaturated fatty acids (72.72-73.28\%) in amaranth seed were reported [32]. Bozorov et al. reported that the predominant saturated fatty acid in amaranth seed was palmitic acid, while the predominant unsaturated fatty acids were linoleic acids and oleic acids [32]. According to He et al., the major fatty acids in the oil from 11 genotypes of 4 grain amaranth species were palmitic (19.1-23.4\%), oleic (18.7-38.9\%) and linoleic (36.7-55.9\%) acids [33]. The linoleic acids represented in amaranth oil are essential fatty acids which cannot be synthetized by the human body and play an important role due to their antiadipogenic, antidiabetogenic, anti-carcinogenic and anti-therosclerotic activities [34]. Based on the fatty acid profile of the amaranth oil, amaranth can be considered a promising food and an important raw material for pharma. 
Table 4. Fatty acid composition of amaranth seed.

\begin{tabular}{lc}
\hline Fatty Acid & mg/100 g Amaranth \\
\hline Dodecanoic acid C12:0 & 0.30 \\
Myristoleic acid C14:0 & 0.52 \\
cis-9-Octadecenoic acid C18:1 & 0.74 \\
Pentadecanoic acid C15:0 & 0.08 \\
Palmitic acid C16:0 & 7.38 \\
cis-9-Palmitoleic acid C16:1 & 0.63 \\
Heptadecanoic Acid C17:0 & 0.16 \\
cis-10-Heptadecenoic acid C17:1 & 0.06 \\
Oleic acid C18:1 & 23.78 \\
trans,trans-9,12-linoleic acid (C18:2) & 3.18 \\
cis,cis-9,12-linoleic acid (C18:2) & 13.53 \\
Arachidic acid (C20:0) & 0.30 \\
Gamma linolenic acid (C18:3) & 3.05 \\
cis-11-Eicosenoic acid (C20:1) & 0.36 \\
Linolenic acid (C18:3) & 0.71 \\
Heneicosanoic acid (C21:0) & 0.08 \\
Eicosadienoic acid (C20:2, cis-11,14) & 0.16 \\
Behenic acid (C22:0) & 0.34 \\
Eicosatetranoic acid (20:3) & 0.05 \\
cis-5,8,11,14-arachidonic acid (C20:4) & 0.19 \\
Tricosanoic acid (C23:0) & 0.06 \\
Nervonic acid (C24:1) & 0.08 \\
TOTAL & 55.71 \\
Saturated fatty acids (\%) & 16.54 \\
Unsaturated fatty acids (\%) & 83.45 \\
Poly-unsaturated fatty acids & 37.56 \\
\hline
\end{tabular}

\subsection{Amino Acid Profile}

Amaranth is a protein-rich pseudo-cereal ( 14.45\%), and the sum of the essential amino acids in the seeds is approximately equal to the recommended FAO and WHO standard [35]. Table 5 presents the composition of amino acids in amaranth seed. There are nine essential amino acids, namely leucine, isoleucine, valine, phenylalanine, threonine, tryptophan, methionine, histidine and lysine [36]. Figure 4 presents a typical chromatogram for the amino acid profile of amaranth seed. As can be observed, all 9 essential amino acids known were reported: histidine, isoleucine, leucine, lysine, methionine, phenylalanine, threonine, tryptophan and valine in a total concentration of $29.67 \mathrm{~g} / 100 \mathrm{~g}$ protein, with the major essential amino acid being lysine, followed by leucine and histidine. According to the FAO and WHO standard, the tryptophan concentration is $1.0 \mathrm{~g} / 100 \mathrm{~g}$ protein, methionine's is $3.5 \mathrm{~g} / 100 \mathrm{~g}$ protein, threonine's is $4.0 \mathrm{~g} / 100 \mathrm{~g}$ protein, isoleucine's is $4.0 \mathrm{~g} / 100 \mathrm{~g}$, valine's is $5.0 / 100 \mathrm{~g}$ protein, lysine's is $5.5 \mathrm{~g} / 100 \mathrm{~g}$ protein, leucine's is $7.0 \mathrm{~g} / 100 \mathrm{~g}$ protein and cysteine's is $3.5 \mathrm{~g} / 100 \mathrm{~g}$ protein. In our study, there were some negative differences with the $\mathrm{FAO}$ and $\mathrm{WHO}$ standard in terms of threonine, isoleucine and valine and positive differences in terms of lysine, leucine, cysteine, methionine and tryptophan. Our results are in agreement with those reported in the literature $[37,38]$. The essential amino acids play an important role in the human body, promoting protein synthesis, influencing the human metabolism, regulating multiple biological processes and influencing body weight and energy balance $[36,39,40]$. 
Table 5. Amino acids present in amaranth seed.

\begin{tabular}{|c|c|}
\hline Amino Acid & g/100 g Protein \\
\hline Alanine & 1.79 \\
\hline Asparagine & 2.87 \\
\hline Aspartic acid & 3.72 \\
\hline Cystathionine & 5.09 \\
\hline Cystine & 6.06 \\
\hline Glutamic acid & 4.95 \\
\hline Glutamine & 0.97 \\
\hline Glycine & 1.03 \\
\hline Histidine * & 6.83 \\
\hline 3-hydroxyproline & 3.34 \\
\hline Isoleucine * & 2.87 \\
\hline Leucine * & 7.85 \\
\hline Lysine * & 10.10 \\
\hline Methionine* & 4.69 \\
\hline Phenylalanine * & 3.80 \\
\hline Proline & 3.83 \\
\hline Hydroxyproline dipeptide & 2.58 \\
\hline Serine & 3.40 \\
\hline Thioproline & 2.40 \\
\hline Threonine * & 3.05 \\
\hline Tryptophan * & 5.51 \\
\hline Tyrosine & 5.30 \\
\hline Valine * & 3.11 \\
\hline$\alpha$-aminopimelic acid & 4.87 \\
\hline
\end{tabular}

* Essential amino acids.

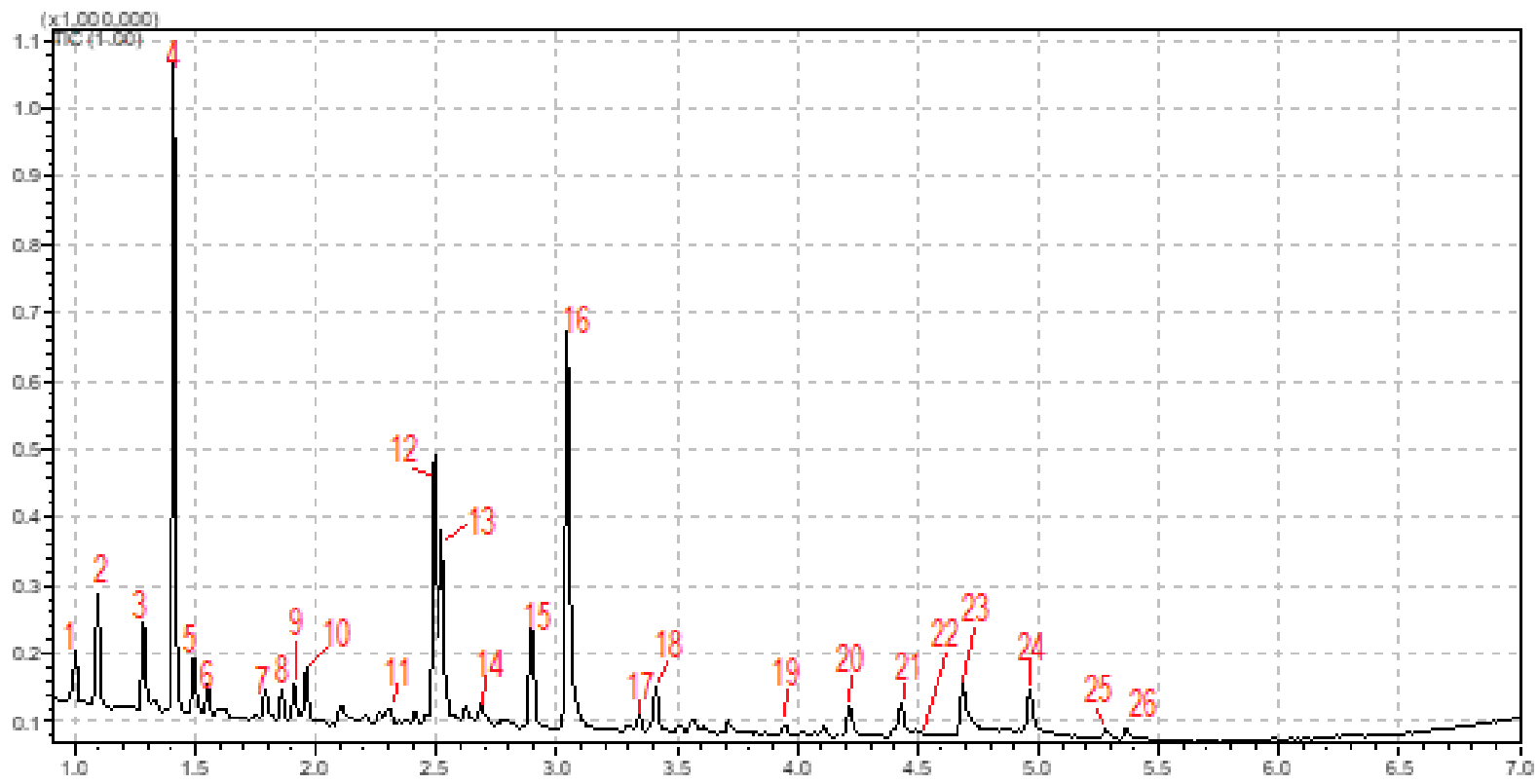

Figure 4. Amaranth seed amino-acid profile: $1=$ alanine, $2=$ glycine, $3=$ valine, $4=$ internal standard, 5 = leucine, 6 = isoleucine, $7=$ threonine, $8=$ serine, $9=$ proline, $10=$ asparagine, $11=$ thioproline, 12 = aspartic acid, 13 = methionine, 14 =3-hydroxyproline, $15=$ phenylalanine, 16 = glutamic acid, $17=\alpha$-aminopimelic acid, $18=$ glutamine, $19=4$-hydroxylserine, $20=$ hydroxyproline dipeptide, 21 = histidine, 22 = lysine, 23 = tyrosine, 24 = tryptophan, $25=$ cystationine, and $26=$ cystine.

\section{Limitations and Future Perspectives}

Our study's limitations are related to the time of extraction. An increase in the extraction time could lead to a higher yield for the TPC and TFC, but the high shear rates of the ultra-turrax could cause a decrease in the TPC and TFC. Future studies will cover 
the hydrothermal impact (e.g., sous-vide treatment) on the amaranth properties (e.g., mass transfer, TPC, TFC and amino acid composition) and the extraction of bioactive compounds from amaranth seed using other techniques (e.g., ultrasonication extraction and microwave extraction).

\section{Conclusions}

Amaranth seed can be considered a valuable source of polyphenols (phenolic acids and flavonoids) and fatty acids. The parameters which influenced the extraction of polyphenols from amaranth seed the most were the solid-to-liquid ratio, methanol concentration and ultra-turrax speed. The Box-Benhken design was suitable for predicting the TPC and TFC using the response surface method. The two models were significant ones $(p<0.05)$, and the F-value was 10.31 for the TPC and 10.29 for the TFC. From the phenolic acids determined, vanillic acid was the most abundant, followed by rosmarinic acid, chlorogenic acid, $p$-coumaric acid and caffeic acid. The most abundant flavonoid was kaempferol, followed by myricetin and luteolin. The fatty acid reported to be of the highest amount was oleic acid ( $23.78 \mathrm{mg} / 100 \mathrm{~g}$ amaranth), representing $42.68 \%$ of the total fatty acids, followed by cis,cis-9,12-linoleic acid (C18:2), palmitic acid C16:0 and trans,trans-9,12-linoleic acid (C18:2). The saturated fatty acids represented $16.54 \%$ of the total, and unsaturated fatty acids represented $83.45 \%$ (poly-unsaturated fatty acids represented $37.56 \%$ ). Nine essential amino acids were reported in amaranth seed-histidine, isoleucine, leucine, lysine, methionine, phenylalanine, threonine, tryptophan and valine-at a total concentration of $29.67 \mathrm{~g} / 100 \mathrm{~g}$ protein, with the major essential amino acid being lysine followed by histidine and methionine. The limits of our experimental work were related to the particle size of the materials, as it is known that the extraction efficiency is influenced by the particle size. In the future, we intend to study the influence of thermal treatments on the phenolic compounds from amaranth seed.

Author Contributions: Conceptualization, O.P. and M.O.; methodology, O.P.; software, M.O.; validation, O.P. and M.O.; formal analysis, O.P. and M.O.; investigation, O.P.; resources, O.P. and M.O.; data curation, O.P. and M.O.; writing—original draft preparation, O.P.; writing—review and editing, O.P. and M.O.; visualization, O.P. and M.O.; supervision, M.O. The authors contributed equally to this research. All authors have read and agreed to the published version of the manuscript.

Funding: This paper was supported by “DECIDE-Development through entrepreneurial education and innovative doctoral and post doctoral research, project code POCU/380/6/13/125031, project cofinanced from the European Social Fund through the 2014-2020 Operational Program Human Capital".

Institutional Review Board Statement: Not applicable.

Informed Consent Statement: Not applicable.

Data Availability Statement: Not applicable.

Conflicts of Interest: The authors declare no conflict of interest.

\section{References}

1. Lamothe, L.M.; Srichuwong, S.; Reuhs, B.L.; Hamaker, B.R. Quinoa (Chenopodium quinoa W.) and amaranth (Amaranthus caudatus L.) provide dietary fibres high in pectic substances and xyloglucans. Food Chem. 2015, 167, 490-496. [CrossRef] [PubMed]

2. Paśko, P.; Sajewicz, M.; Gorinstein, S.; Zachwieja, Z. Analysis of selected phenolic acids and flavonoids in Amaranthus cruentus and Chenopodium quinoa seeds and sprouts by HPLC. Acta Chromatogr. 2008, 20, 661-672. [CrossRef]

3. Rodríguez, M.; Tironi, V.A. Polyphenols in amaranth (A. manteggazianus) flour and protein isolate: Interaction with other components and effect of the gastrointestinal digestion. Food Res. Int. 2020, 137, 109524. [CrossRef]

4. Venskutonis, P.R.; Kraujalis, P. Nutritional Components of Amaranth Seeds and Vegetables: A Review on Composition, Properties, and Uses. Compr. Rev. Food Sci. Food Saf. 2013, 12, 381-412. [CrossRef]

5. Sandoval-Sicairos, E.S.; Milán-Noris, A.K.; Luna-Vital, D.A.; Milán-Carrillo, J.; Montoya-Rodríguez, A. Anti-inflammatory and antioxidant effects of peptides released from germinated amaranth during in vitro simulated gastrointestinal digestion. Food Chem. 2021, 343, 128394. [CrossRef]

6. Vacek, J.; Ulrichová, J.; Klejdus, B.; Imánek, V. Analytical methods and strategies in the study of plant polyphenolics in clinical samples. Anal. Methods 2010, 2, 604-613. [CrossRef] 
7. Berti, C.; Riso, P.; Brusamolino, A.; Porrini, M. Effect on appetite control of minor cereal and pseudocereal products. Br. J. Nutr. 2005, 94, 850-858. [CrossRef]

8. Gorinstein, S.; Vargas, O.J.M.; Jaramillo, N.O.; Salas, I.A.; Ayala, A.L.M.; Arancibia-Avila, P.; Toledo, F.; Katrich, E.; Trakhtenberg, S. The total polyphenols and the antioxidant potentials of some selected cereals and pseudocereals. Eur. Food Res. Technol. 2007, 225, 321-328. [CrossRef]

9. Paśko, P.; Bartoń, H.; Fołta, M.; Gwizdz, J. Evaluation of antioxidant activity of amaranth (Amaranthus cruentus) grain and by-products (flour, popping, cereal). Rocz. Państw. Zakł. Hig. 2007, 58, 35-40.

10. Barba de la Rosa, A.P.; Fomsgaard, I.S.; Laursen, B.; Mortensen, A.G.; Olvera-Martínez, L.; Silva-Sánchez, C.; Mendoza-Herrera, A.; González-Castañeda, J.; De León-Rodríguez, A. Amaranth (Amaranthus hypochondriacus) as an alternative crop for sustainable food production: Phenolic acids and flavonoids with potential impact on its nutraceutical quality. J. Cereal Sci. 2009, 49, 117-121. [CrossRef]

11. Manach, C.; Scalbert, A.; Morand, C.; Rémésy, C.; Jiménez, L. Polyphenols: Food sources and bioavailability. Am. J. Clin. Nutr. 2004, 79, 727-747. [CrossRef] [PubMed]

12. Scalbert, A.; Johnson, I.T.; Saltmarsh, M. Polyphenols: Antioxidants and beyond. Am. J. Clin. Nutr. 2005, 81, 215S-217S. [CrossRef] [PubMed]

13. Ozsoy, N.; Yilmaz, T.; Kurt, O.; Can, A.; Yanardag, R. In vitro antioxidant activity of Amaranthus lividus L. Food Chem. 2009, 116, 867-872. [CrossRef]

14. Alvarez-Jubete, L.; Wijngaard, H.; Arendt, E.K.; Gallagher, E. Polyphenol composition and in vitro antioxidant activity of amaranth, quinoa buckwheat and wheat as affected by sprouting and baking. Food Chem. 2010, 119, 770-778. [CrossRef]

15. Repo-Carrasco-Valencia, R.; Hellström, J.K.; Pihlava, J.M.; Mattila, P.H. Flavonoids and other phenolic compounds in Andean indigenous grains: Quinoa (Chenopodium quinoa), kañiwa (Chenopodium pallidicaule) and kiwicha (Amaranthus caudatus). Food Chem. 2010, 120, 128-133. [CrossRef]

16. Barbin, D.F.; Natsch, A.; Müller, K. Improvement of functional properties of rapeseed protein concentrates produced via alcoholic processes by thermal and mechanical treatments. J. Food Process. Preserv. 2011, 35, 369-375. [CrossRef]

17. Adiamo, O.Q.; Gbadamosi, O.S.; Abiose, S.H. Functional Properties and Protein Digestibility of Protein Concentrates and Isolates Produced from Kariya (Hildergadia bateri) Seed. J. Food Process. Preserv. 2016, 40. [CrossRef]

18. Xu, W.J.; Zhai, J.W.; Cui, Q.; Liu, J.Z.; Luo, M.; Fu, Y.J.; Zu, Y.G. Ultra-turrax based ultrasound-assisted extraction of five organic acids from honeysuckle (Lonicera japonica Thunb.) and optimization of extraction process. Sep. Purif. Technol. 2016, 166, 73-82. [CrossRef]

19. Scholz, P.; Keck, C.M. Nanoemulsions produced by rotor-stator high speed stirring. Int. J. Pharm. 2015, 482, 110-117. [CrossRef]

20. Jin, M.M.; Zhang, W.D.; Song, G.S.; Xu, Y.M.; Du, Y.F.; Guo, W.; Cao, L.; Xu, H.J. Discrimination and Chemical Phylogenetic Study of Four Pulsatilla Herbs Using UPLC-ESI-MS/MS Combined with Hierarchical Cluster Analysis. J. Chromatogr. Sci. 2018, 56, 216-224. [CrossRef]

21. Cheng, Z.; Song, H.; Yang, Y.; Zhou, H.; Liu, Y.; Liu, Z. Smashing Tissue Extraction of Five Lignans from the Fruit of Schisandra chinensis. J. Chromatogr. Sci. 2016, 54, 246-256. [CrossRef]

22. Yin, X.S.; Zhong, Z.F.; Bian, G.L.; Cheng, X.J.; Li, D.Q. Ultra-rapid, enhanced and eco-friendly extraction of four main flavonoids from the seeds of Oroxylum indicum by deep eutectic solvents combined with tissue-smashing extraction. Food Chem. 2020, 319, 126555. [CrossRef] [PubMed]

23. Pauliuc, D.; Dranca, F.; Oroian, M. Antioxidant activity, total phenolic content, individual phenolics and physicochemical parameters suitability for Romanian honey authentication. Foods 2020, 9, 306. [CrossRef] [PubMed]

24. Oroian, M.; Ursachi, F.; Dranca, F. Ultrasound-assisted extraction of polyphenols from crude pollen. Antioxidants 2020, 9, 322. [CrossRef]

25. Urcan, A.C.; Criste, A.D.; Dezmirean, D.S.; Bobiș, O.; Bonta, V.; Dulf, F.V.; Mărgăoan, R.; Cornea-Cipcigan, M.; Campos, M.G. Botanical origin approach for a better understanding of chemical and nutritional composition of beebread as an important value-added food supplement. LWT 2021, 142, 111068. [CrossRef]

26. Tabaraki, R.; Heidarizadi, E.; Benvidi, A. Optimization of ultrasonic-assisted extraction of pomegranate (Punica granatum L.) peel antioxidants by response surface methodology. Sep. Purif. Technol. 2012, 98, 16-23. [CrossRef]

27. Antoniewska, A.; Rutkowska, J.; Pineda, M.M.; Adamska, A. Antioxidative, nutritional and sensory properties of muffins with buckwheat flakes and amaranth flour blend partially substituting for wheat flour. LWT -Food Sci. Technol. 2018, 89, 217-223. [CrossRef]

28. El-kott, A.F.; Abd-Lateif, A.E.K.M.; Khalifa, H.S.; Morsy, K.; Ibrahim, E.H.; Bin-Jumah, M.; Abdel-Daim, M.M.; Aleya, L. Kaempferol protects against cadmium chloride-induced hippocampal damage and memory deficits by activation of silent information regulator 1 and inhibition of poly (ADP-Ribose) polymerase-1. Sci. Total Environ. 2020, 728, 138832. [CrossRef]

29. Alagal, R.I.; AlFaris, N.A.; Alshammari, G.M.; ALTamimi, J.Z.; AlMousa, L.A.; Yahya, M.A. Kaempferol attenuates doxorubicinmediated nephropathy in rats by activating SIRT1 signaling. J. Funct. Foods 2022, 89, 104918. [CrossRef]

30. Fan, L.; Zhao, X.; Tong, Q.; Zhou, X.; Chen, J.; Xiong, W.; Fang, J.; Wang, W.; Shi, C. Interactions of Dihydromyricetin, a Flavonoid from Vine Tea (Ampelopsis grossedentata) with Gut Microbiota. J. Food Sci. 2018, 83, 1444-1453. [CrossRef]

31. Sun, W.L.; Li, X.Y.; Dou, H.Y.; Wang, X.D.; Li, J.D.; Shen, L.; Ji, H.F. Myricetin supplementation decreases hepatic lipid synthesis and inflammation by modulating gut microbiota. Cell Rep. 2021, 36, 109641. [CrossRef] [PubMed] 
32. Bozorov, S.S.; Berdiev, N.S.; Ishimov, U.J.; Olimjonov, S.S.; Ziyavitdinov, J.F.; Asrorov, A.M.; Salikhov, S.I. Chemical composition and biological activity of seed oil of amaranth varieties. Nova Biotechnol. Chim. 2018, 17, 66-73. [CrossRef]

33. He, H.P.; Cai, Y.; Sun, M.; Corke, H. Extraction and purification of squalene from Amaranthus grain. J. Agric. Food Chem. 2002, 50, 368-372. [CrossRef] [PubMed]

34. Zhang, Z.S.; Kang, Y.J.; Che, L. Composition and thermal characteristics of seed oil obtained from Chinese amaranth. LWT 2019, 111,39-45. [CrossRef]

35. Thoufeek Ahamed, N.; Singhai, R.S.; Kulkarni, P.R.; Pal, M. A lesser-known grain, Chenopodium quinoa: Review of the chemical composition of its edible parts. Food Nutr. Bull. 1998, 19. [CrossRef]

36. Xiao, F.; Guo, F. Impacts of essential amino acids on energy balance. Mol. Metab. 2021, 57, 101393. [CrossRef] [PubMed]

37. López, D.N.; Galante, M.; Robson, M.; Boeris, V.; Spelzini, D. Amaranth, quinoa and chia protein isolates: Physicochemical and structural properties. Int. J. Biol. Macromol. 2018, 109, 152-159. [CrossRef]

38. Thanapornpoonpong, S.N.; Vearasilp, S.; Pawelzik, E.; Gorinstein, S. Influence of various nitrogen applications on protein and amino acid profiles of amaranth and quinoa. J. Agric. Food Chem. 2008, 56, 11464-11470. [CrossRef]

39. Tashiro, Y.; Han, Q.; Tan, Y.; Sugisawa, N.; Yamamoto, J.; Nishino, H.; Inubushi, S.; Higuchi, T.; Aoki, T.; Murakami, M.; et al. Oral recombinant methioninase prevents obesity in mice on a high-fat diet. In Vivo (Brooklyn) 2020, 34, 489-494. [CrossRef]

40. Drummen, M.; Tischmann, L.; Gatta-Cherifi, B.; Adam, T.; Westerterp-Plantenga, M. Dietary protein and energy balance in relation to obesity and co-morbidities. Front. Endocrinol. (Lausanne) 2018, 9, 443. [CrossRef] 